\title{
Epigenetic Silencing of Tumor Suppressor lncRNA NKILA: Implication on NF-кB Signaling in Non-Hodgkin's Lymphoma
}

\author{
Min-Yue Zhang ${ }^{1,2}$, George Calin ${ }^{3}$, Ming-Dan Deng ${ }^{1}{ }^{(}$, , Rex K. H. Au-Yeung ${ }^{4}{ }^{\circledR}$, Lu-Qian Wang ${ }^{1}$ \\ and Chor-Sang Chim ${ }^{1, *}$
}

1 Department of Medicine, Queen Mary Hospital, The University of Hong Kong, Hong Kong, China; zhangminyue@connect.hku.hk (M.-Y.Z.); u3003939@connect.hku.hk (M.-D.D.); wanglucy@hku.hk (L.-Q.W.)

2 Division of Hematology, School of Medicine, Renji Hospital, Shanghai Jiaotong University, Shanghai 200127, China

3 Department of Experimental Therapeutics, The University of Texas MD Anderson Cancer Center, Houston, TX 77030, USA; gcalin@mdanderson.org

4 Department of Pathology, Queen Mary Hospital, The University of Hong Kong, Hong Kong, China; rex.auyeung@hku.hk

* Correspondence: jcschim@hku.hk; Tel.: +852-2255-4769; Fax: +852-2816-2187

check for updates

Citation: Zhang, M.-Y.; Calin, G.; Deng, M.-D.; Au-Yeung, R.K.H.; Wang, L.-Q.; Chim, C.-S. Epigenetic Silencing of Tumor Suppressor lncRNA NKILA: Implication on NF- $\kappa$ B Signaling in Non-Hodgkin's Lymphoma. Genes 2022, 13, 128. https://doi.org/10.3390/ genes13010128

Academic Editor: Haiyang Yun

Received: 7 December 2021

Accepted: 6 January 2022

Published: 11 January 2022

Publisher's Note: MDPI stays neutral with regard to jurisdictional claims in published maps and institutional affiliations.

Copyright: (C) 2022 by the authors. Licensee MDPI, Basel, Switzerland. This article is an open access article distributed under the terms and conditions of the Creative Commons Attribution (CC BY) license (https:// creativecommons.org/licenses/by/ $4.0 /)$.

\begin{abstract}
The long non-coding RNA (lncRNA) NKILA, localized to 20q13.31, is a negative regulator of NF- $\mathrm{BB}$ signaling implicated in carcinogenesis. As a $\mathrm{CpG}$ island is embedded in the promoter region of NKILA, it is hypothesized as a tumor suppressor lncRNA silenced by promoter DNA methylation in non-Hodgkin's lymphoma (NHL). By pyrosequencing-verified methylation-specific PCR, NKILA methylation was detected in 1/10 (10\%) NHL cell lines, but not in normal peripheral blood buffy coats or tonsils. NKILA methylation correlated with the repression of NKILA in cell lines. Hypomethylation treatment with 5-Aza-2'-deoxycytidine resulted in promoter demethylation and the re-expression of NKILA. In 102 NHL primary samples, NKILA was methylated in 29 (51.79\%) diffuse large B-cell lymphoma (DLBCL) and $4(20 \%)$ peripheral T-cell lymphoma cases, but unmethylated in all 26 mantle cell lymphoma cases. Mechanistically, the knockdown of NKILA resulted in promoting $\mathrm{IkB} \alpha$ phosphorylation, associated with nucleus translocation of total p65 and phosphorylated p65 in SU-DHL-1 cells, hence constitutive NF- $\mathrm{kB}$ activation. Functionally, the knockdown of NKILA in SU-DHL-1 cells led to decreased cell death and increased cellular proliferation. Collectively, NKILA was a tumor suppressor lncRNA frequently hypermethylated in DLBCL. Promoter DNA methylationmediated NKILA silencing resulted in increased cellular proliferation and decreased cell death via the repression of NF-kB signaling in NHL.
\end{abstract}

Keywords: DNA methylation; NKILA; non-Hodgkin's lymphoma; tumor suppressor; NF- $\kappa B$ signaling

\section{Introduction}

Non-Hodgkin's lymphoma (NHL) encompasses a heterogeneous group of diseases, including B-cell, T-cell and natural killer (NK)-cell lymphoma based on the origin and lineage of tumor cells [1]. B-cell lymphoma comprises more than $70 \%$ of all lymphomas, while T-cell lymphoma accounts for $10-15 \%$ of all lymphomas [2]. Diffuse large B-cell lymphoma (DLBCL) and follicular lymphoma are the two most common subtypes of NHL [3], whereas NK-cell lymphoma is an aggressive subtype rare in Western countries [4]. The incidence of NHL was 6.7/100,000 among males and 4.7/100,000 among females worldwide, which ranked as the 8 th and 10th of all types of cancers, respectively [5]. The clinical features of NHL patients include painless lymphadenopathy, organomegaly and the presence or absence of B symptoms (night sweats, weight loss $>10 \%$ and fever with temperature $>38^{\circ} \mathrm{C}$ ) [6]. 
DNA methylation refers to the addition of methyl group $\left(-\mathrm{CH}_{3}\right)$ to $\mathrm{C} 5$ position of cytosine in a CpG dinucleotide via DNA methyltransferases [7]. Cancer cells are characterized by two major alterations of DNA methylation: global DNA hypomethylation but the gene-specific DNA hypermethylation of promoter-associated CpG island [8]. Moreover, promoter DNA hypermethylation-mediated reversible silencing of tumor suppressor protein-coding genes, including PTPL1 [9] and SHP1 [10,11], and tumor suppressive microRNAs (miRs), including $m i R-155-3 p$ [12] and miR-146a [13], has been implicated in lymphomagenesis.

Long non-coding RNAs (lncRNAs) are broadly defined as a class of non-coding RNAs measuring $>200$ nucleotides [14,15]. IncRNAs play essential roles in regulating multiple biological processes, including cellular metabolism, organogenesis and carcinogenesis [16-18]. LncRNA, NKILA (NF-KappaB Interacting LncRNA), localized to 20q13.31, was firstly found to be downregulated in breast cancer. Overexpression of NKILA resulted in the inhibition of metastasis and the increase in apoptosis by repression of NF- $\mathrm{BB}$ signaling activity in breast cancer cells, indicating the tumor suppressor property of NKILA [19]. Moreover, the NF- $\mathrm{B}$ signaling pathway is constitutively activated and, hence, implicated in the pathogenesis of NHL. However, the function of NKILA in lymphoma remains unknown.

As a CpG island is present at the promoter region of NKILA, we postulated that NKILA is a tumor suppressor lncRNA reversibly silenced by promoter DNA methylation in NHL. Herein, the methylation of NKILA will be studied in NHL, and the role of NKILA in lymphomagenesis will also be investigated.

\section{Materials and Methods}

\subsection{Patient Samples}

A total of 102 formalin fixed, paraffin-embedded (FFPE) or fresh frozen diagnostic lymph node biopsy tissues, including 56 DLBCL, and 26 mantle cell lymphoma (MCL) and 20 peripheral T-cell lymphoma (PTCL) cases, were acquired from 5 hospitals in Hong Kong, China (Queen Mary Hospital, Kwong Wah Hospital, Princess Margaret Hospital, United Christian Hospital and Pamela Youde Nethersole Eastern Hospital). The diagnosis of lymphoma was based on the WHO (World Health Organization, Geneva, Switzerland) classification [20]. Eleven FFPE tonsil tissues were also obtained from healthy individuals undergoing tonsillectomy. Our study was approved by the Institutional Review Board of Queen Mary Hospital.

\subsection{Cell Culture}

Five MCL cell lines (SP53, REC-1, GRANTA-519, MINO and JEKO-1), two DLBCL cell lines (SU-DHL-6 and SU-DHL-16), two ALK (+) anaplastic large cell lymphoma (ALCL) cell lines (KARPAS-299 and SU-DHL-1) and one T-cell lymphoblastic lymphoma cell line (SUP-T1) were used in this study. SP53 and REC-1 were kindly provided by Professor Raymond Lai (Department of Laboratory Medicine and Pathology, University of Alberta and Cross Cancer Institute). Other cell lines were purchased from Deutsche Sammlung von Mikroogranismen und Zellkulturen (DSMZ) (Braunschweig, Germany). Cell lines were maintained in RPMI-1640 (DMEM for GRANTA-519) supplemented with 10-15\% fetal bovine serum, $50 \mathrm{U} / \mathrm{mL}$ of penicillin and $50 \mathrm{ug} / \mathrm{mL}$ streptomycin in a humidified atmosphere of $5 \% \mathrm{CO}_{2}$ at $37^{\circ} \mathrm{C}$.

\subsection{DNA Demethylation Treatment}

SU-DHL-6 cells $\left(1 \times 10^{6}\right.$ cells $\left./ \mathrm{mL}\right)$ were seeded in $25 \mathrm{~cm}^{2}$ flasks and cultured with 0.5-1.5 $\mu \mathrm{M}$ of 5-aza-2'-deoxycytidine (5-azadC) (Sigma-Aldrich) for 7 days. The 5-azadC was replaced every $24 \mathrm{~h}$. Afterwards, the cells were harvested for DNA and RNA extraction.

\subsection{DNA Extraction}

DNA from NHL cell lines and healthy peripheral blood was extracted with a DNA Blood Mini kit (Qiagen). DNA extraction from frozen patient biopsies was conducted with 
an automated DNA extraction system (DNA Tissue Kit from Qiagen). DNA extraction from FFPE tissues were performed by using QIAamp DNA FFPE Tissue Kit (Qiagen).

\subsection{Methylation-Specific Polymerase Chain Reaction (MSP)}

Sodium bisulfite conversion was conducted with an EpiTect Bisulfite Kit (Qiagen). Afterwards, MSP was performed in bisulfite-treated DNA with two sets of primers, which were specific to unmethylated (U-MSP) or methylated (M-MSP) DNA sequences. MSP primers were designed at the CpG island upstream to the NKILA gene by the online tool Methprimer (http:/ / www.urogene.org/methprimer/ (accessed on 31 May 2019). Details of the primer sequence and PCR condition for MSP are listed in Table 1. For each MSP reaction, the enzymatically methylated control DNA (CpGenome Universal Methylated DNA; Chemicon/Millipore, Billerica, MA, USA) was used as the positive control for M-MSP and the negative control for U-MSP.

Table 1. Primer sequences and PCR reaction conditions for NKILA.

\begin{tabular}{|c|c|c|c|c|}
\hline & Forward Primer $\left(5^{\prime}\right.$ to $\left.3^{\prime}\right)$ & Reverse Primer $\left(5^{\prime}\right.$ to $\left.3^{\prime}\right)$ & Tm/Cycles/ 2 & Reference \\
\hline \multicolumn{5}{|c|}{ Methylation-Specific PCR (MSP) } \\
\hline M-MSP & $\begin{array}{l}\text { TAG GTA GAC GGT TTG } \\
\text { ACG TTA GC }\end{array}$ & $\begin{array}{c}\text { GAA AAA ACC TCG ACG } \\
\text { AAA ATT AAC G }\end{array}$ & $57^{\circ} \mathrm{C} / 35 \times / 2 \mathrm{mM}$ & \\
\hline U-MSP & $\begin{array}{c}\text { GGT AGG TAG ATG GTT } \\
\text { TGA TGT TAG T }\end{array}$ & $\begin{array}{c}\text { ACA AAA AAA CCT CAA } \\
\text { CAA AAA TTA ACA }\end{array}$ & $55^{\circ} \mathrm{C} / 37 \mathrm{x} / 1.5 \mathrm{mM}$ & \\
\hline \multicolumn{5}{|c|}{ Semi-Quantitative RT-PCR/Quantitative Real-Time RT-PCR } \\
\hline NKILA & $\begin{array}{c}\text { AAC CAA ACC TAC CCA } \\
\text { CAA CG }\end{array}$ & $\begin{array}{c}\text { ACC ACT AAG TCA ATC } \\
\text { CCA GGT G }\end{array}$ & $\begin{array}{c}55^{\circ} \mathrm{C} / 40 \times / 2 \mathrm{mM} \\
\text { (Semi-Quantitative } \\
\text { RT-PCR) }\end{array}$ & [19] \\
\hline GAPDH & $\begin{array}{c}\text { ACC ACA GTC CAT GCC } \\
\text { ATC ACT }\end{array}$ & $\begin{array}{c}\text { TCC ACC ACC CTG TTG } \\
\text { CTG TA }\end{array}$ & $\begin{array}{c}60^{\circ} \mathrm{C} / 24 \times / 1.5 \mathrm{mM} \\
\text { (Semi-Quantitative } \\
\text { RT-PCR) }\end{array}$ & [21] \\
\hline
\end{tabular}

Key: M-MSP, MSP for methylated alleles; U-MSP, MSP for unmethylated alleles and Tm, annealing temperature.

\subsection{Quantitative Reverse Transcription Polymerase Chain Reaction (qRT-PCR)}

Total RNA was isolated with a Direct-zol ${ }^{\mathrm{TM}}$ RNA MiniPrep kit (Zymo Research), followed by reverse transcription with SuperScript ${ }^{\circledR}$ III (Invitrogen, Carlsbad, CA, USA). The qRT-PCR was performed with a SYBR ${ }^{\circledR}$ Select Master Mix (ABI, Bedford, MA, USA), and the human glyceraldehyde 3-phosphate dehydrogenase (GAPDH) was used as the endogenous control. The relative quantity of NKILA expression was calculated by the method of $2^{-\triangle \Delta C t}$ and normalized against the endogenous control. The primer sequences for NKILA and GAPDH are listed in Table $1[19,21]$.

\subsection{Quantitative Bisulfite Pyrosequencing}

The promoter region of NKILA overlapped with the amplicon of MSP was amplified in the bisulfite converted DNA with methylation-unbiased primers. Primer sequences and condition for PCR were listed as follows: forward primer, 5'-GTT GGG GAG AGG GTA TAG-3'; reverse primer, $5^{\prime}$-Biotin-CTC CTC CTC CTC ATT CAA ATC- $3^{\prime}$ and condition, $56{ }^{\circ} \mathrm{C} / 45$ x/1.5 mM MgCl 2 . A Qiagen PyroMark PCR Kit was employed to perform PCR amplification. Afterwards, a stretch of DNA containing 10 consecutive $\mathrm{CpG}$ dinucleotides were pyrosequenced with a sequencing primer, 5'-GTT AGG GGA GGG GGT G-3', on a PSQ 96MA system and analyzed using PyroQ-CpG 1.0.9. software.

\subsection{Knockdown of NKILA}

RNA interference by small interfering RNA (siRNA) was used to knockdown the expression of NKILA. Briefly, SU-DHL-1 cells were seeded at a density of $0.5 \times 10^{6} / \mathrm{mL}$ in a six-well plate and transfected with NKILA siRNA (n541256, Ambion, Austin, TX, USA) or 
Silencer Negative Control (Ambion) at a final concentration of $150 \mathrm{nM}$ with an RNAiMAX transfection reagent (Invitrogen, Carlsbad, CA, USA). The transfected cells were cultured for $24 \mathrm{~h}$ or $48 \mathrm{~h}$.

\subsection{Cell Proliferation and Cell Death}

After $24 \mathrm{~h}$ and $48 \mathrm{~h}$ transfection, viable cells were analyzed by trypan blue exclusion and the cell number was measured by the Countess II (Invitrogen). Cell proliferation was calculated by normalization with the negative control at $48 \mathrm{~h}$ post-transfection. Cell death was analyzed by trypan blue exclusion at $24 \mathrm{~h}$ post-transfection. All experiments were repeated at least three times.

\subsection{Western Blot}

SU-DHL-1 cells transfected with NKILA siRNA and Silencer Negative Control were treated with $200 \mathrm{ng} / \mathrm{mL}$ TNF $\alpha$ for 1 hour before being lysed in RIPA buffer (Cell signaling). Totally, $15 \mu \mathrm{g}$ protein of each sample was loaded and separated in Mini-PROTEAN TGXTM Precast gel (Bio-rad, Hercules, CA, USA), followed by transference onto a $0.45 \mu \mathrm{m}$ PVDF membrane (Amersham, Chiltern, Buckinghamshire, UK). The membrane was blocked in a super blocking buffer and incubated in primary antibodies, including p65 (1:1000, cell signaling); p-p65 ser536 (1:1000, cell signaling); IkB $\alpha$ (1:1000, cell signaling); p-IkB $\alpha$ ser32 (1:1000, cell signaling); $\beta$-tubulin (1:1000, cell signaling) and nucleolin (1:1000, cell signaling) at $4{ }^{\circ} \mathrm{C}$ overnight with a gentle rotation. The membrane was then washed and incubated with HRP-linked secondary antibodies, anti-mouse (1:3000, cell signaling) and anti-rabbit (1:3000, cell signaling) for one hour, followed by TBST washing. The ECL HARP substrate was used on the membrane before being developed in X-ray films.

Nuclear and cytosol fractionations of SU-DHL-1 cells were prepared by the Nuclear/Cytosol Fractionation Kit (BioVision, Milpitas, CA, USA), according to the manufacturers' instructions. Western blot was then performed in these samples.

\subsection{Statistical Analysis}

The difference of cell proliferation and cell death between SU-DHL-1 cells transfected with NKILA siRNA and Silencer Negative Control were compared by Student's $t$-test. The difference of the NKILA methylation frequency in different subtypes of NHL primary samples was analyzed by the $\chi^{2}$ test. All $p$-values were 2 -sided; $p<0.05$ was considered as the significant difference.

\section{Results}

\subsection{NKILA Was Methylated in a Tumor-Specific Manner in NHL Cells}

NKILA was reported to repress the NF- $\mathrm{B}$ signaling pathway [19,22,23], which is constitutively activated and implicated in lymphomagenesis. There is a $\mathrm{CpG}$ island at the promoter region of NKILA. Hence, the methylation status of NKILA was investigated by MSP in the bisulfite-converted DNA of normal healthy controls, including 10 peripheral blood buffy coats and 11 normal tonsil tissues, in addition to 10 NHL cell lines. Direct sequencing of M-MSP products from methylated positive control DNA demonstrated that all unmethylated cytosines were converted into thymidines after PCR, whereas all methylated cytosines remained unchanged, indicating the complete bisulfite conversion and specificity of MSP (Figure 1A). By MSP, the methylation of NKILA was absent in all of normal peripheral blood buffy coats and normal tonsil tissues (Figure 1B). Amongst NHL cell lines, NKILA was completely methylated (MM) in SU-DHL-6 and completely unmethylated (UU) in GRANTA-519, JEKO-1, MINO, REC-1, SP-53, KARPAS-299 and SU-DHL-1. However, neither U-MSP nor M-MSP signals were observed in SUP-T1 cells (Figure 1C). Furthermore, the methylation status of NKILA in NHL cell lines detected by MSP was verified by quantitative bisulfite pyrosequencing. SU-DHL-6 cells with a complete methylation of NKILA had a mean methylation percentage of $69.4 \%$. In contrast, NHL cell lines with complete unmethylation of NKILA had a mean methylation percentage 
ranging from $5.0 \%$ to $6.5 \%$, which confirmed the methylation status detected by MSP (Figure 1D). These results indicated that NKILA was methylated in a tumor-specific manner in NHL cells.

(A) Wild-type Methylated
GCGGGGGCCGGGGAGGGGGCGCGCGCTGCGCCAATCCCCGCCGAGGT GCGGGGGTCGGGGAGGGGGCGCGCGTTGCGTTAATTTTCGTCGAGGT

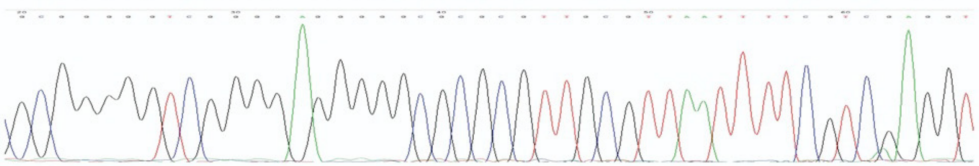

(B)

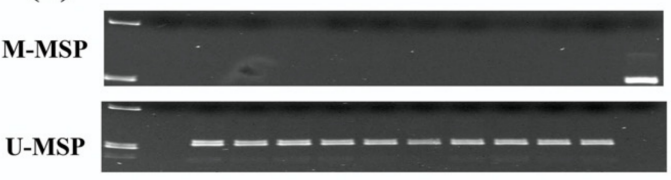

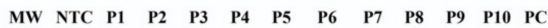

M-MSP

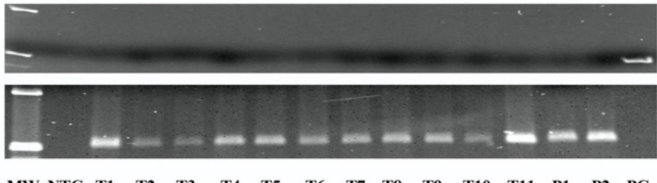

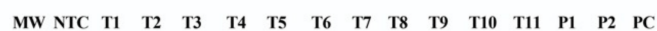

(C)

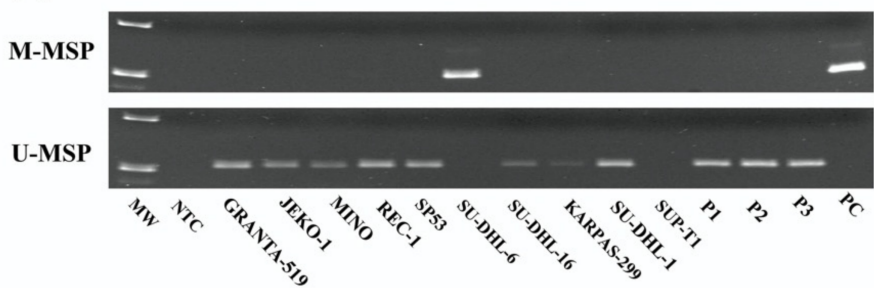

U-MSP: unmethylated MSP; M-MSP: methylated MSP

MW: marker; NTC: no template control

P1-10: normal peripheral blood control

T1-11: normal tonsil control

PC: positive control with methylated DNA

(D)
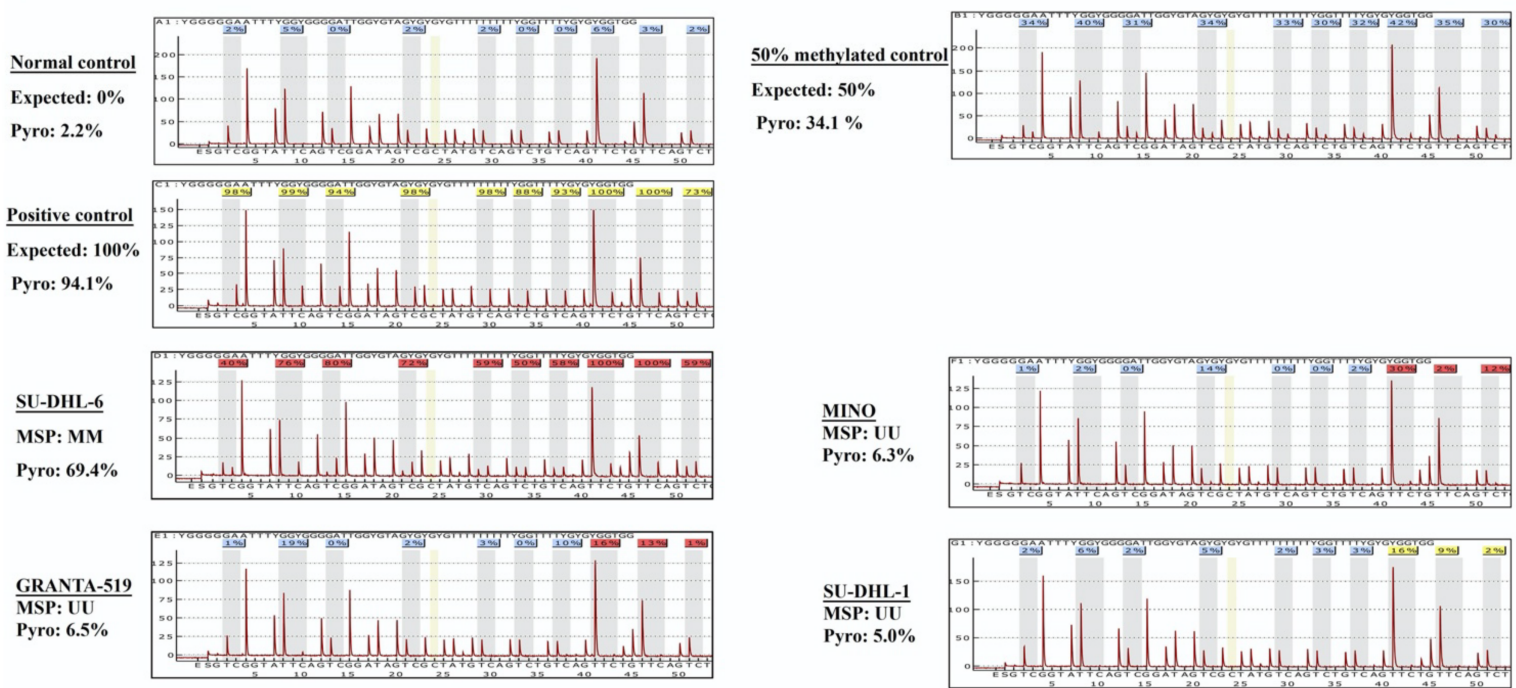

Expected: 50\%

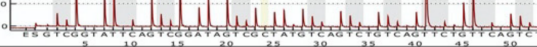
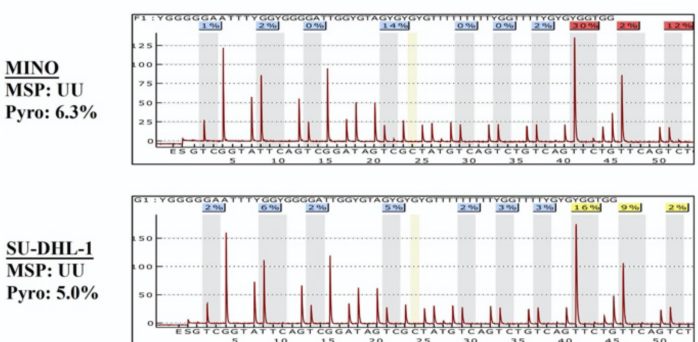

Figure 1. Methylation of NKILA in normal controls and NHL cell lines. (A) Direct sequencing of M-MSP products from a positive control with methylated DNA. (B) M- and U-MSP demonstrate that NKILA is unmethylated in normal peripheral blood buffy coats (P1-P10) and normal tonsil tissues (T1-T11). (C) M- and U-MSP show that NKILA is completely methylated in SU-DHL-6 cell lines and completely unmethylated in GRANTA-519, JEKO-1, MINO, REC-1, SP-53, KARPAS-299 and SU-DHL-1 cell lines. Both M-MSP and U-MSP are absent in SUP-T1 cell lines. (D) Quantitative bisulfite pyrosequencing analysis show the mean methylation percentage of 10 neighboring CpG dinucleotides overlapping with MSP amplicon in $0 \%, 50 \%$ and $100 \%$ methylation control, and NHL cell lines.

\subsection{The Expression of NKILA Was Inversely Correlated with Promoter DNA Methylation}

To explore the relationship between promoter DNA methylation and the expression of NKILA, semi-quantitative RT-PCR of NKILA was performed in NHL cell lines. 
As demonstrated by the DNA gel, no expression of NKILA was detected in SU-DHL-6 cells that was completely methylated for NKILA. Conversely, the expression of NKILA was observed in other cell lines completely unmethylated for NKILA (Figure 2A).

A

AKILA

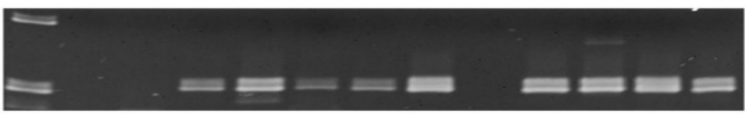

GAPDH

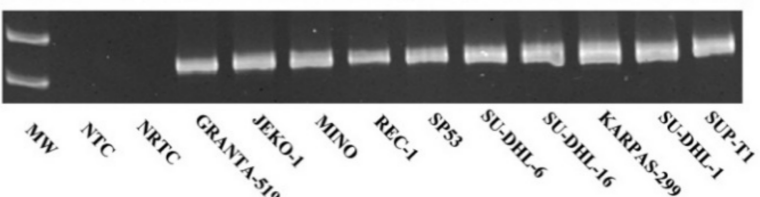

MW: marker; NTC: no template control;

NRTC: non reverse transcriptase control;

P1, P2 : normal peripheral blood control;

PC: positive control with methylated DNA

B

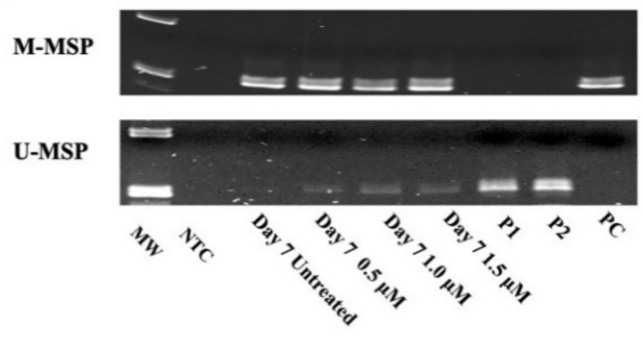

C

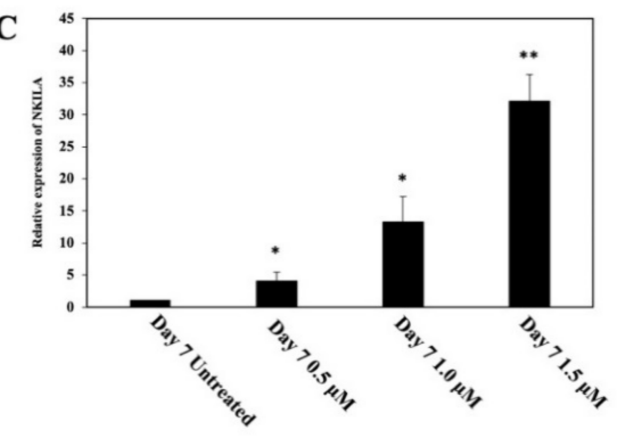

Figure 2. Correlation of promoter DNA methylation of NKILA and its expression in NHL cell lines. (A) NKILA methylation measured by MSP is associated with a lower expression of NKILA in NHL cell lines by semi-quantitative RT-PCR. (B,C) Treatment of SU-DHL-6 cells completely methylated for NKILA with 5-AzadC for 7 days, leads to NKILA promoter demethylation detected by MSP (B) and associated with the re-expression of NKILA by qRT-PCR (C). Columns represent mean $+/-1 \mathrm{SD}$ from three qRT-PCR experiments in triplicate. *: Compared with untreated cells, $p$-value $<0.05, * *$ : Compared with untreated cells, $p$-value $<0.01$.

Furthermore, to study whether promoter DNA methylation was associated with reversible silencing of NKILA, SU-DHL-6 cells, which were completely methylated for NKILA, were treated with a demethylating agent, 5-AzadC, for 7 days. Upon treatment with 5-AzadC, the promoter of NKILA was demethylated, as illustrated by the emergence of U-MSP signal (Figure 2B), with the re-expression of NKILA (Figure 2C). Hence, these data suggested that the reversible silencing of NKILA was mediated by promoter DNA methylation in NHL cells.

\subsection{NKILA Was Differentially Methylated in NHL Primary Samples}

To investigate the methylation of NKILA in NHL primary samples, MSP was performed with bisulfite-converted DNA in primary samples, including $26 \mathrm{MCL}, 56 \mathrm{DLBCL}$ and 20 PTCL cases. The MSP results showed that no methylation of NKILA was detected in primary MCL samples (Figure 3A). However, NKILA was found to be methylated in 29 (51.79\%) DLBCL and 4 (20\%) PTCL cases (Figure 3B,C), hence preferentially methylated in DLBCL than MCL $(p<0.0001)$ and PTCL $(p=0.007)$. 


\section{A}

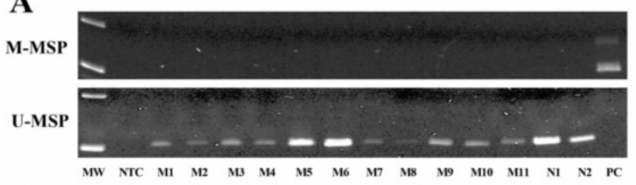

C

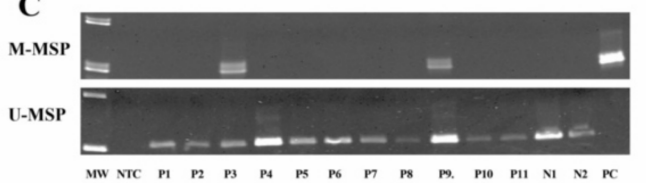

\section{B}

M-MSP

U-MSP

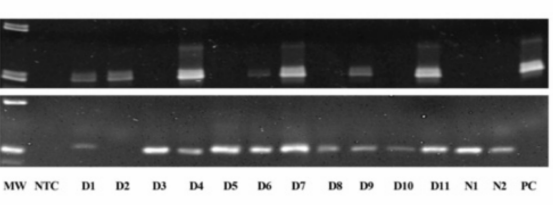

MW: marker: NTC: no template control; N1,2: normal peripheral blood control

PC: positive control with methylated DNA; M1-11: MCL primary samples

D1-11: DLBCL primary samples; P1-11: PTCL primary samples

Figure 3. Methylation status of NKILA is demonstrated in different types of NHL primary samples by MSP. Representative M- and U-MSP shows the methylation of NKILA in MCL (A), DLBCL (B) and PTCL (C).

\subsection{NKILA Inhibited IkB $\alpha$ Phosphorylation and NF- $\kappa B$ Activation}

NKILA has been reported to suppress NF- $\mathrm{kB}$ signaling pathways by blocking $\operatorname{IkB} \alpha$ phosphorylation in breast cancer, non-small cell lung cancer and nasopharyngeal carcinoma $[19,22,23]$. To elucidate NKILA function in lymphoma, NKILA-targeted siRNA was used to knockdown NKILA and non-targeting siRNA was used as a control in SU-DHL-1 cells. The qRT-PCR result confirmed that NKILA was knocked down at $24 \mathrm{~h}$ and $48 \mathrm{~h}$ posttransfection (Figure 4A). To further evaluate NKILA function in NF- $\mathrm{KB}$ signaling pathways, we examined IkB $\alpha$ phosphorylation and p65 nucleus translocation after NKILA knockdown, with an augmentation of the NF-KB signaling by TNF $\alpha$ [19]. The result showed that NKILA knockdown led to an increase in IkB $\alpha$ phosphorylation in SU-DHL-1 cells at both $24 \mathrm{~h}$ and $48 \mathrm{~h}$ post-transfection (Figure $4 \mathrm{~B}$ ), which was associated with enhanced p65 being translocated into the nucleus, compared with the control. Moreover, the enhanced nuclear translocation of phosphorylated p65 ser536 was observed after NKILA knockdown (Figure 4C). These results collectively indicated that NKILA negatively regulated NF- $\mathrm{kB}$ signaling pathways, by inhibiting $\mathrm{IkB} \alpha$ phosphorylation and reducing nuclear translocation of total and phosphorylated p65. 
A

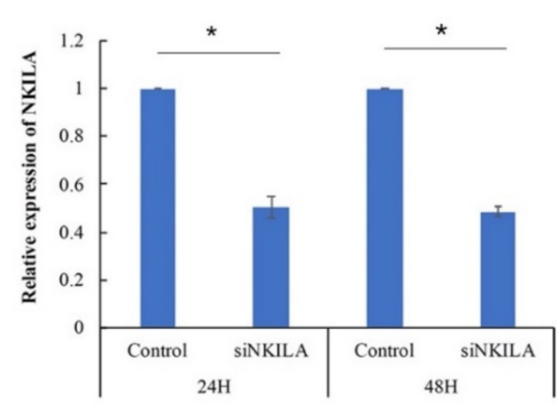

C

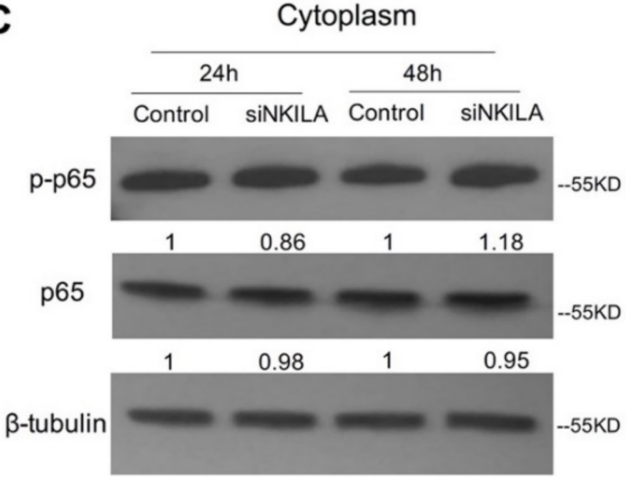

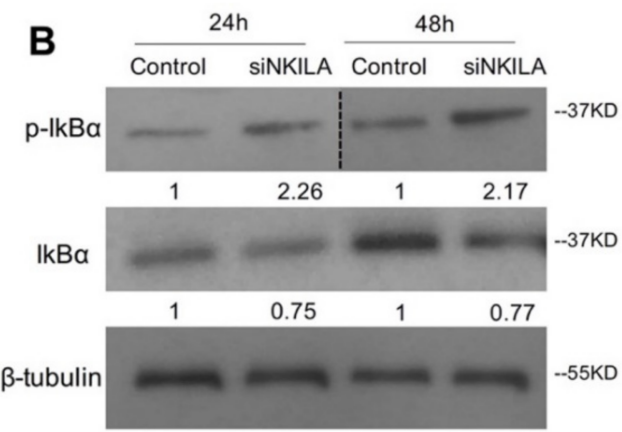

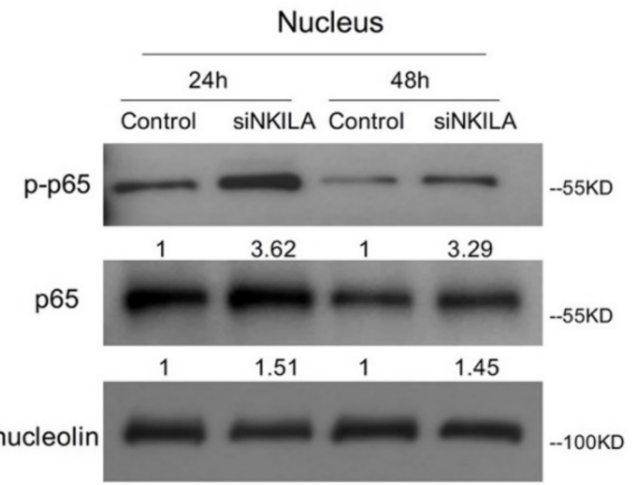

Figure 4. NKILA knockdown leads to more I $\kappa \mathrm{B} \alpha$ phosphorylation and more $\mathrm{p} 65$ translocated into the nucleus. (A) qRT-PCR was performed to examine NKILA knockdown efficiency in SU-DHL-1 at $24 \mathrm{~h}$ and $48 \mathrm{~h}$ post-transfection. Columns represent mean $+/-1 \mathrm{SD}$ from three independent experiments. *: $p$-value $<0.05$. (B) Western blot shows the total IкB $\alpha$ and phosphorylated I $\kappa \mathrm{B} \alpha$ ser32 expression level. $\beta$-tubulin was used as the loading control. Quantification densitometry of each band is

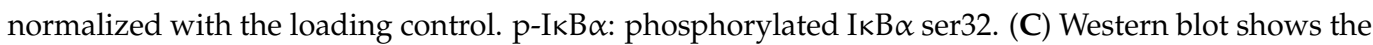
total p65 and phosphorylated p65 ser536 level in the cytoplasm and nucleus. $\beta$-tubulin and nucleolin serves as the loading control for the cytoplasm and nucleus, respectively. p-p65: phosphorylated p65 ser536; siNKILA: NKILA-targeted siRNA. 24 h: 24 h post-transfection; 48 h: 48-h post-transfection.

\subsection{NKILA Was a Tumor Suppressor IncRNA in SU-DHL-1 Cells}

As NKILA was a negative regulator in NF-kB signaling pathways, its tumor suppressor function in lymphoma was further explored by examining cell proliferation and cell death in SU-DHL-1 cells that were completely unmethylated for NKILA. The knockdown of NKILA led to a significantly increased cell proliferation rate compared with the control (Figure 5A). Furthermore, the knockdown of NKILA resulted in reduced cell death in SU-DHL-1 cells (Figure 5B). These results supportively indicated NKILA acted as a tumor suppressor lncRNA in SU-DHL-1 cells. 
A

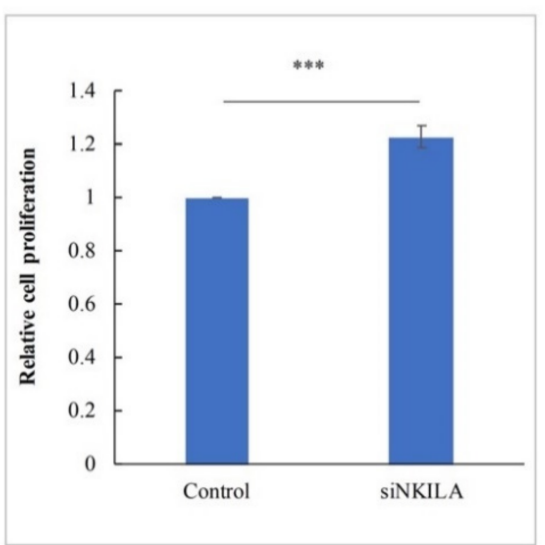

B

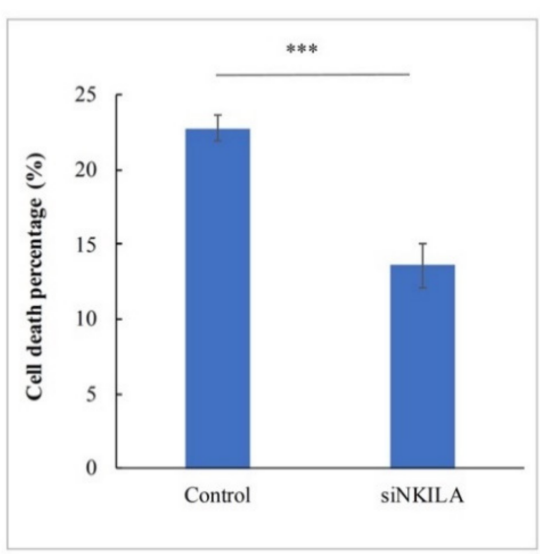

Figure 5. NKILA suppresses cell growth and promotes cell death in SU-DHL-1. (A) Cellular proliferation upon knockdown of NKILA is studied using the trypan blue assay at $48 \mathrm{~h}$ post-transfection. Columns represent mean +/- 1SD from five independent experiments. (B) Cell death upon knockdown of NKILA is studied using the trypan blue exclusion assay at $24 \mathrm{~h}$ post-transfection. Columns represent mean +/- 1SD from three independent experiments. siNKILA: NKILA-targeted siRNA. ***: $p$-value $<0.001$.

\section{Discussion}

Several observations were made in this study. Firstly, we showed that NKILA was methylated in NHL cell lines and NHL primary samples, but unmethylated in normal controls, hence methylated in a tumor-specific manner in NHL. This was consistent with a tumor-specific pattern of the methylation of tumor suppressor protein-coding genes, such as $p 16$ and $p 15$ [24], and non-coding tumor suppressor microRNAs, such as miR-342-3p [25] and miR-1250-5p [26], in NHL. However, this contrasted with the tissue- but not tumorspecific pattern of methylation, such as miR-373 [27] and miR-127 [28], which were shown to be methylated in both normal counterparts and tumor cells, hence likely unimportant in carcinogenesis.

Secondly, in primary NHL samples, NKILA was frequently methylated in DLBCL, but not in MCL or PTCL samples. Indeed, NHL is highly heterogenous with different genetic and epigenetic features [1,20]. For instance, a microarray-based DNA methylation study in 367 hematological neoplasms demonstrated that promoter DNA hypermethylation was more frequent in precursor B and T lymphoid neoplasias and mature B-cell lymphomas of a germinal center origin (such as DLBCL, FL and Burkitt's lymphoma), than in mature T-cell lymphomas, such as PTCL [29]. Therefore, differential methylation of NKILA can be accounted for the difference in cell origin and their inherent pathogenetic mechanisms.

Thirdly, to our knowledge, this is the first study that reported that promoter DNA methylation mediated the reversible silencing of NKILA in NHL, which is evidenced by an inverse correlation between the NKILA methylation and its expression in NHL cell lines, and the re-expression of NKILA upon demethylation treatment in cell lines with a complete methylation of NKILA. Apart from promoter DNA methylation, NKILA have been reported to be regulated by other mechanisms. For instance, Huang et al. [30] showed that, in cytotoxic T lymphocytes, NKILA transcription induced by antigen stimulation was mediated by an increase in the acetylation of histones (H4ac, H3K27ac and H3K9ac) at the promoter region of NKILA, suggesting the expression of NKILA regulated by histone modification. In addition, in breast cancer cells, some oncogenic microRNAs, such as $m i R$ 103 or miR-107, could directly target and downregulate the expression of NKILA, which was confirmed by the luciferase reporter assay [19].

Fourthly, NKILA was first shown to suppress NF- $\mathrm{BB}$ signaling in breast cancer. It can directly bind to the NF- $\mathrm{B} / \mathrm{I} \kappa \mathrm{B}$ complex, and potentially mask the phosphorylation site of $I \kappa B$, thereby suppressing IKK-induced I $k$ B phosphorylation and, hence, NF- $k B$ activity [19]. As the constitutive activation of the NF- $\kappa B$ signaling pathway is the hallmark 
of many lymphoid malignancies, including Hodgkin's lymphoma and DLBCL [31], and hence implicated in lymphomagenesis, it is essential to comprehend the precise function of NKILA and its interaction with NF- $\mathrm{kB}$ in lymphomas. To the best of our knowledge, this is the first study showing the role of NKILA in lymphomas. Previous studies reported that phosphorylation p65 at ser536 led to the enhanced transcriptional activity of NF$\kappa \mathrm{B}$ [32-34]. We observed that the knockdown of NKILA led to the upregulation of NF- $\mathrm{B}$ signaling pathways by promoting I $\mathrm{K} \mathrm{B} \alpha$ phosphorylation, and the consequent nuclear translocation of total p65 and phosphorylated p65 in lymphoma cells. Furthermore, as a transcription factor, NF- $\mathrm{kB}$ regulates the expression of multiple downstream effectors, enhancing cell proliferation, inhibiting cell apoptosis or promoting cell migration and invasion [35]. Herein, in NHL cells, the downregulation of NKILA resulted in an increase in cellular proliferation and decrease in cell death, consistent with the tumor suppressor role of NKILA in multiple tumors, including melanoma, lung cancer, rectal cancer, laryngeal cancer and breast cancer $[19,22,36-40]$. In addition, NKILA has also been shown to inhibit tumor invasion and migration in epithelial cancers, such as breast cancer, hepatocellular carcinoma and tongue squamous cell carcinoma $[19,39,40]$. Collectively, these results suggested that the NKILA can inhibit cellular proliferation and induce cell death by suppressing the NF- $\mathrm{B}$ signaling pathway in NHL cells.

\section{Conclusions}

Taken together, the epigenetic silencing of lncRNA NKILA was mediated by promoter DNA methylation in a tumor-specific manner in NHL. Frequent hypermethylation of NKILA was preferentially detected in DLBCL patients. NKILA exerted its tumor suppressive property by the inhibition of cellular proliferation and increase of cell death, in association with suppression of the NF- $\kappa B$ signaling pathway via inducing I $\mathrm{B} \alpha$ phosphorylation, and the consequent nucleus translocation of total p65 and phosphorylated p65 in NHL cells.

Author Contributions: Conceptualization, C.-S.C. and G.C.; methodology, M.-Y.Z.; software, M.-D.D.; validation, M.-D.D. and L.-Q.W.; formal analysis, M.-Y.Z.; investigation, L.-Q.W.; resources, R.K.H.A.Y.; data curation, M.-D.D.; writing—original draft preparation, M.-Y.Z. and M.-D.D.; writing—review and editing, C.-S.C. and G.C.; visualization, R.K.H.A.-Y.; supervision, G.C.; project administration, C.-S.C.; funding acquisition, C.-S.C. All authors have read and agreed to the published version of the manuscript.

Funding: This work was supported by the Health and Medical Research Fund (05163456) and the Food and Health Bureau, HKSAR awarded to Chor Sang Chim. The funders had no role in the design of the study and collection, analysis, and interpretation of data and in writing the manuscript.

Institutional Review Board Statement: The study was conducted according to the guidelines of the Declaration of Helsinki, and approved by the Institutional Review Board of Queen Mary Hospital (UW 05-269 T/932)

Informed Consent Statement: Informed consent was obtained from all subjects involved in the study.

Data Availability Statement: All data generated or analyzed during this study are included in this published article.

Acknowledgments: We thank Kwan Yeung Wong for the technical advice in the experiments.

Conflicts of Interest: The authors declare no conflict of interest.

\section{References}

1. Swerdlow, S.H.; Campo, E.; Pileri, S.A.; Harris, N.L.; Stein, H.; Siebert, R.; Advani, R.; Ghielmini, M.; Salles, G.A.; Zelenetz, A.D.; et al. The 2016 revision of the World Health Organization classification of lymphoid neoplasms. Blood 2016, 127, 2375-2390. [CrossRef]

2. Au, W.Y.; Ma, S.Y.; Chim, C.S.; Choy, C.; Loong, F.; Lie, A.K.; Lam, C.C.; Leung, A.Y.; Tse, E.; Yau, C.C.; et al. Clinicopathologic features and treatment outcome of mature T-cell and natural killer-cell lymphomas diagnosed according to the World Health Organization classification scheme: A single center experience of 10 years. Ann. Oncol. 2005, 16, 206-214. [CrossRef]

3. Bowzyk Al-Naeeb, A.; Ajithkumar, T.; Behan, S.; Hodson, D.J. Non-Hodgkin lymphoma. BMJ 2018, 362, k3204. [CrossRef] 
4. $\quad$ Chim, C.S.; Ma, S.Y.; Au, W.Y.; Choy, C.; Lie, A.K.; Liang, R.; Yau, C.C.; Kwong, Y.L. Primary nasal natural killer cell lymphoma: Long-term treatment outcome and relationship with the International Prognostic Index. Blood 2004, 103, 216-221. [CrossRef] [PubMed]

5. Bray, F.; Ferlay, J.; Soerjomataram, I.; Siegel, R.L.; Torre, L.A.; Jemal, A. Global cancer statistics 2018: GLOBOCAN estimates of incidence and mortality worldwide for 36 cancers in 185 countries. CA Cancer J. Clin. 2018, 68, 394-424. [CrossRef]

6. Shankland, K.R.; Armitage, J.O.; Hancock, B.W. Non-Hodgkin lymphoma. Lancet 2012, 380, 848-857. [CrossRef]

7. Esteller, M. Epigenetics in cancer. N. Engl. J. Med. 2008, 358, 1148-1159. [CrossRef]

8. Klutstein, M.; Nejman, D.; Greenfield, R.; Cedar, H. DNA Methylation in Cancer and Aging. Cancer Res. 2016, 76, 3446-3450. [CrossRef] [PubMed]

9. Wang, W.; Wang, J.; Li, Z.; Zhu, M.; Zhang, Z.; Wang, Y.; Jing, H. Promoter hypermethylation of PTPL1, PTPN6, DAPK, p16 and 5-azacitidine inhibits growth in DLBCL. Oncol. Rep. 2016, 35, 139-146. [CrossRef] [PubMed]

10. Chim, C.S.; Wong, K.Y.; Loong, F.; Srivastava, G. SOCS1 and SHP1 hypermethylation in mantle cell lymphoma and follicular lymphoma: Implications for epigenetic activation of the Jak/STAT pathway. Leukemia 2004, 18, 356-358. [CrossRef]

11. Molavi, O.; Wang, P.; Zak, Z.; Gelebart, P.; Belch, A.; Lai, R. Gene methylation and silencing of SOCS3 in mantle cell lymphoma. Br. J. Haematol. 2013, 161, 348-356. [CrossRef]

12. Yim, R.L.; Wong, K.Y.; Kwong, Y.L.; Loong, F.; Leung, C.Y.; Chu, R.; Lam, W.W.; Hui, P.K.; Lai, R.; Chim, C.S. Methylation of miR-155-3p in mantle cell lymphoma and other non-Hodgkin's lymphomas. Oncotarget 2014, 5, 9770-9782. [CrossRef]

13. Paik, J.H.; Jang, J.Y.; Jeon, Y.K.; Kim, W.Y.; Kim, T.M.; Heo, D.S.; Kim, C.W. MicroRNA-146a downregulates NFkappaB activity via targeting TRAF6 and functions as a tumor suppressor having strong prognostic implications in NK/T cell lymphoma. Clin. Cancer Res. 2011, 17, 4761-4771. [CrossRef]

14. Kopp, F.; Mendell, J.T. Functional Classification and Experimental Dissection of Long Noncoding RNAs. Cell 2018, $172,393-407$. [CrossRef] [PubMed]

15. Wang, K.C.; Chang, H.Y. Molecular mechanisms of long noncoding RNAs. Mol. Cell 2011, 43, 904-914. [CrossRef]

16. Spizzo, R.; Almeida, M.I.; Colombatti, A.; Calin, G.A. Long non-coding RNAs and cancer: A new frontier of translational research? Oncogene 2012, 31, 4577-4587. [CrossRef]

17. Grote, P.; Herrmann, B.G. Long noncoding RNAs in organogenesis: Making the difference. Trends Genet. 2015, 31, 329-335. [CrossRef]

18. Fatica, A.; Bozzoni, I. Long non-coding RNAs: New players in cell differentiation and development. Nat. Rev. Genet. 2014, 15, 7-21. [CrossRef] [PubMed]

19. Liu, B.; Sun, L.; Liu, Q.; Gong, C.; Yao, Y.; Lv, X.; Lin, L.; Yao, H.; Su, F.; Li, D.; et al. A cytoplasmic NF-kappaB interacting long noncoding RNA blocks IkappaB phosphorylation and suppresses breast cancer metastasis. Cancer Cell 2015, 27, 370-381. [CrossRef]

20. Swerdlow, S.H.; Campo, E.; Harris, N.L.; Jaffe, E.S.; Pileri, S.A.; Stein, H.; Thiele, J.; Vardiman, J.W. WHO Classification of Tumours of Haematopoietic and Lymphoid Tissues; International Agency for Research on Cancer: Lyon, France, 2008.

21. Chim, C.S.; Wong, K.Y.; Qi, Y.; Loong, F.; Lam, W.L.; Wong, L.G.; Jin, D.Y.; Costello, J.F.; Liang, R. Epigenetic inactivation of the miR-34a in hematological malignancies. Carcinogenesis 2010, 31, 745-750. [CrossRef] [PubMed]

22. Lu, Z.; Li, Y.; Wang, J.; Che, Y.; Sun, S.; Huang, J.; Chen, Z.; He, J. Long non-coding RNA NKILA inhibits migration and invasion of non-small cell lung cancer via NF-kappaB/Snail pathway. J. Exp. Clin. Cancer Res. 2017, 36, 54. [CrossRef]

23. Zhang, W.; Guo, Q.; Liu, G.; Zheng, F.; Chen, J.; Huang, D.; Ding, L.; Yang, X.; Song, E.; Xiang, Y.; et al. NKILA represses nasopharyngeal carcinoma carcinogenesis and metastasis by NF-kappaB pathway inhibition. PLoS Genet. 2019, 15, e1008325. [CrossRef]

24. Chim, C.S.; Wong, K.Y.; Loong, F.; Lam, W.W.; Srivastava, G. Frequent epigenetic inactivation of Rb1 in addition to p15 and p16 in mantle cell and follicular lymphoma. Hum. Pathol. 2007, 38, 1849-1857. [CrossRef] [PubMed]

25. Zhang, M.Y.; Calin, G.A.; Yuen, K.S.; Jin, D.Y.; Chim, C.S. Epigenetic silencing of miR-342-3p in B cell lymphoma and its impact on autophagy. Clin. Epigenet. 2020, 12, 150. [CrossRef]

26. Zhang, M.Y.; Wang, L.Q.; Chim, C.S. miR-1250-5p is a novel tumor suppressive intronic miRNA hypermethylated in nonHodgkin's lymphoma: Novel targets with impact on ERK signaling and cell migration. Cell Commun. Signal. 2021, 19, 62. [CrossRef] [PubMed]

27. Lujambio, A.; Ropero, S.; Ballestar, E.; Fraga, M.F.; Cerrato, C.; Setien, F.; Casado, S.; Suarez-Gauthier, A.; Sanchez-Cespedes, M.; Git, A.; et al. Genetic unmasking of an epigenetically silenced microRNA in human cancer cells. Cancer Res. 2007, 67, 1424-1429. [CrossRef]

28. Saito, Y.; Liang, G.; Egger, G.; Friedman, J.M.; Chuang, J.C.; Coetzee, G.A.; Jones, P.A. Specific activation of microRNA-127 with downregulation of the proto-oncogene BCL6 by chromatin-modifying drugs in human cancer cells. Cancer Cell 2006, 9, 435-443. [CrossRef] [PubMed]

29. Martin-Subero, J.I.; Ammerpohl, O.; Bibikova, M.; Wickham-Garcia, E.; Agirre, X.; Alvarez, S.; Bruggemann, M.; Bug, S.; Calasanz, M.J.; Deckert, M.; et al. A comprehensive microarray-based DNA methylation study of 367 hematological neoplasms. PLoS ONE 2009, 4, e6986. [CrossRef] [PubMed]

30. Huang, D.; Chen, J.; Yang, L.; Ouyang, Q.; Li, J.; Lao, L.; Zhao, J.; Liu, J.; Lu, Y.; Xing, Y.; et al. NKILA lncRNA promotes tumor immune evasion by sensitizing T cells to activation-induced cell death. Nat. Immunol. 2018, 19, 1112-1125. [CrossRef] 
31. Nagel, D.; Vincendeau, M.; Eitelhuber, A.C.; Krappmann, D. Mechanisms and consequences of constitutive NF-kappaB activation in B-cell lymphoid malignancies. Oncogene 2014, 33, 5655-5665. [CrossRef]

32. Chen, L.F.; Williams, S.A.; Mu, Y.; Nakano, H.; Duerr, J.M.; Buckbinder, L.; Greene, W.C. NF-kappaB RelA phosphorylation regulates RelA acetylation. Mol. Cell Biol. 2005, 25, 7966-7975. [CrossRef]

33. Kwon, H.J.; Choi, G.E.; Ryu, S.; Kwon, S.J.; Kim, S.C.; Booth, C.; Nichols, K.E.; Kim, H.S. Stepwise phosphorylation of p65 promotes NF-kappaB activation and NK cell responses during target cell recognition. Nat. Commun. 2016, 7, 11686. [CrossRef]

34. Sakurai, H.; Chiba, H.; Miyoshi, H.; Sugita, T.; Toriumi, W. IkappaB kinases phosphorylate NF-kappaB p65 subunit on serine 536 in the transactivation domain. J. Biol. Chem. 1999, 274, 30353-30356. [CrossRef]

35. Karin, M.; Greten, F.R. NF-kappaB: Linking inflammation and immunity to cancer development and progression. Nat. Rev. Immunol. 2005, 5, 749-759. [CrossRef]

36. Bian, D.; Gao, C.; Bao, K.; Song, G. The long non-coding RNA NKILA inhibits the invasion-metastasis cascade of malignant melanoma via the regulation of NF-kB. Am. J. Cancer Res. 2017, 7, 28-40.

37. Tao, F.; Xu, Y.; Yang, D.; Tian, B.; Jia, Y.; Hou, J.; Dong, M. LncRNA NKILA correlates with the malignant status and serves as a tumor-suppressive role in rectal cancer. J. Cell Biochem. 2018, 119, 9809-9816. [CrossRef]

38. Yang, T.; Li, S.; Liu, J.; Yin, D.; Yang, X.; Tang, Q. lncRNA-NKILA/NF-kappaB feedback loop modulates laryngeal cancer cell proliferation, invasion, and radioresistance. Cancer Med. 2018, 7, 2048-2063. [CrossRef] [PubMed]

39. Yu, X.; Tang, W.; Yang, Y.; Tang, L.; Dai, R.; Pu, B.; Feng, C.; Xia, J. Long noncoding RNA NKILA enhances the anti-cancer effects of baicalein in hepatocellular carcinoma via the regulation of NF-kappaB signaling. Chem. Biol. Interact. 2018, 285, 48-58. [CrossRef] [PubMed]

40. Huang, W.; Cui, X.; Chen, J.; Feng, Y.; Song, E.; Li, J.; Liu, Y. Long non-coding RNA NKILA inhibits migration and invasion of tongue squamous cell carcinoma cells via suppressing epithelial-mesenchymal transition. Oncotarget 2016, 7, 62520-62532. [CrossRef] [PubMed] 